\title{
Teachers' Perspectives Surrounding ICT Use amongst SEN Students in the Mainstream Educational Setting
}

\author{
Mohaned Ghazi Abed ${ }^{1, *}$ \\ ${ }^{1}$ Institute of Educational Graduate Studies, King Abdulaziz University, Jeddah, Saudi Arabia \\ *Correspondence: Institute of Educational Graduate Studies, King Abdulaziz University, Jeddah, Saudi Arabia. \\ E-mail: mabed@kau.edu.sa
}

Received: December 13, 2017

Accepted: January 17, 2018 Online Published: January 29, 2018

doi:10.5430/wje.v8n1p6

URL: https://doi.org/10.5430/wje.v8n1p6

\begin{abstract}
At the present time, ICT (Information and Communication Technology) is recognised as a pressing consideration in educational establishments worldwide. Accordingly, the present research proved to be valuable to teaching staff, teachers in (Special Educational Needs) SEN and leaders in schools. This work's aim was centred on explaining and examining the viewpoints and experiences of teachers in regard to the adoption of ICT for learners with SEN (Special Educational Needs) in the overall learning setting, and identifying the relationship between inclusion and ICT. Moreover, the various approaches and conditions centred on making ICT more inclusive have been established. Qualitative interviews were carried out with a sample of twenty teachers, the findings of which suggest the adoption of ICT for learners with SEN of all ages; more specifically, computer systems were widely used for word processing alongside writing. ICT may be applied in an effort to fill the void in terms of inclusion whilst accordingly counterbalancing any contribution and differences in terms of the inclusion of those learners with SEN. However, in an effort to achieve this, there is a need for teaching to be adapted to the needs of students, with pedagogy needing to be incorporated alongside technology. In regard to further research, suggestions could include more comparable researches or researches concerning the potential of one-to-one for those students with SEN.
\end{abstract}

Keywords: teachers' perspectives, ICT, special educational needs, inclusion, information and communications technology

\section{Introduction}

Running a school with the ability to accommodate all children is challenging in the modern-day world. In 1994, there was the international recognition of the inclusion movement, with attention afforded to the Salamanca Statement (UNESCO, 1994), which was implemented by a total of 89 countries across the globe, with inclusive education highlighted as outlining the need for schools to accommodate all learners. The key underlying factor associated with inclusive schools is based on the view that all children should be taught and should learn in one setting, whenever feasible, with mainstream institutions needing to accept and accordingly react in line with the varying requirements of learners, whilst further ensuring on-going support and services in line with such requirements.

Inclusion is promoted and highlighted by the national curriculum; nonetheless, within special circumstances, special education may be delivered on an individual basis, or otherwise through separate groups. Regardless of attention that has been garnered by inclusion, Swedish law continues to permit that learners be taken out of their standard learning setting, with a tendency to witness a greater degree of student exclusion in Swedish school environments (Giota \& Emanuelsson, 2011).

In its different forms, ICT is recognised as bridging the gap and accordingly facilitating inclusion for those learners with SEN (Sik-Lányi, Hoogerwerf, Miesenberger \& Cudd, 2015). In the field of ICT, development is quick, with new technological tools and programs introduced on a daily basis. Significant investments are made by schools in the ICT domain, with ICT recognised as enabling students with SEN to be included in the classroom setting, thus allowing them to work alongside their peers, and use assistive technology in an effort to provide learners with the ability to fulfil educational goals (Brodin, 2010). A number of researches highlight the ability of ICT to help learners with SEN, particularly those with writing and/or learning difficulties, through the use of softwares providing word 
prediction capacities, word processors, grammar and spelling facilities, software centred on text-to-speech, voice recognition, as well as planning and organising instruments, for example (Peterson-Karlan, 2011). There seem to be a number of benefits offered by ICT when considering learners with ICT, and assistive technology could prove valuable when used by such learners within their classes, and therefore could promote the concept of inclusion.

\section{Literature Review}

ICT application amongst those with SEN is interesting when considered from a special educational standpoint owing to the fact that the special education teacher's objective is centred on establishing, examining and becoming involved in prevention, and to overcome difficulties and obstacles in the various learning settings (Margalit, 2011). Special education teachers, in the field of ICT centred on learners with SEN, have a varying role to play. Nevertheless, in order to fulfil the objective detailed above, teachers' viewpoints in regard to ICT for learners with SEN should be considered, alongside the inclusion problem, in an effort to provide teaching staff with support in the case of faculty who work with and meet such learners on a day-to-day basis. With rapidly developing ICT and new curriculums, the modern-day world is fast-changing, which places a significant responsibility on the shoulders of teaching staff. Undoubtedly, adapting teaching in mind of all types of student is a complicated undertaking, and teaching learners with the application of assistive technology also places additional responsibilities on teachers. Importantly, a school of an inclusive nature necessitates teaching staff ensuring adherence to the curriculum and accordingly adapting their teachings so as to ensure students' needs are fulfilled, whilst teachers also being well informed and knowledgeable concerning new technology, and have the capacity to integrate technology with pedagogy and content.

A large volume of research has been carried out in the field of ICT for those learners with SEN in the general educational environment, with specific emphasis placed on ICT for those students with writing or reading difficulties. However, when considering the viewpoints of teaching staff in regard to working with learners with SEN in a mainstream educational environment, implementing ICT, very little documentation was identified, with a significant lack of scientific papers corresponding to the area under examination. This, in addition to the ever-increasing investments being made in new technology in Saudi educational environments, requires further research.

\subsection{ICT Application}

This part of the research includes studies identified in regard to ICT application for learners with SEN. Firstly, studies pertaining to the benefits and overall efficiency will be discussed, with the recognised value associated with modifying such assistive technology to the unique requirements of students considered, as well as the knowledge of teachers in regard to how ICT can be implemented for learners with SEN. Lastly, studies need to be identified in regards the different applications of ICT in the teaching environment.

\subsection{ICT Use amongst Learners with SEN}

ICT is recognised as potentially valuable for learners with SEN, particularly those with writing and/or writing problems, with assistive technology helping through word-prediction softwares, grammar and spelling instruments, word processors, programs focused on text-to-speech functionality, voice recognition, and planning and organising instruments, for example (Maor, Currie \& Drewry, 2011).

In a British literature review carried out by Williams, Jamali \& Nicholas (2006), the advantages pertaining to ICT in specific regards special needs were identified, as established through the literature, academic journals and reports published by the government in the teaching, social science and information science domains. The work maintains the view surrounding the various advantages to be garnered by dyslexics when implementing ICT programs centred on computer programs geared towards reading and writing. Nonetheless, through facilitating educational learning, ICT is also positioned to provide other groups of student, such as those with behavioural and emotional problems, with various benefits.

Evidence-based studies show support for the efficiency of ICT in regard to the writing of students. In an American literature review, more than 80 researches were examined in light of whether ICT can be considered advantageous for learners with SEN through the use of writing tools (Peterson-Karlan, 2011). The research suggests that word processing tools provide benefits for learners in regard to writing production, and that the ease of use associated with word processors and text-to-speech programs help to improve levels of writing accuracy. However, although the findings suggest that the use of word-prediction, speech-to-text, grammar checkers and voice recognition programmes provide advantages, there is not enough research in this area to clarify such findings. The outcomes associated with assistive technology in regards organising and planning are not able to be validated through the study examined. 


\subsection{Technology Adaptations on an Individual Basis}

ICT may be a useful instrument for learners with SEN; however, it is essential to consider individual needs and accordingly to adapt technology on a student-to-student basis in line with a review of research concerning ICT efficiency amongst learners with SEN, such as that carried out by Maor et al. (2011). Importantly, works of a scientific nature, notably spanning the past six years and carried out in the field of assistive technology for speech and spelling, and reading and writing, have undergone identification and examination, with most researches found to be from the USA, although there was the inclusion of studies from Israel, the UK and Scandinavia. Importantly, no general conclusions were drawn in regard to the most efficiency programs owing to the fact that the review included a wealth of programs. Most of the findings emphasise that the students' spelling, reading and writing improved through the use of assistive technology. Although there were some exceptions, where learners were found to show no improvement following the adoption of ICT, the conclusion was drawn that assistive technology tools can be beneficial, but that these need to be adapted in line with the learner's individual requirements. In this vein, the needs of students need to be considered, with students' families also needing to be involved prior to the introduction of such instruments. If this is not done, IT abandonment may be witnessed, which can stem from various factors, including complicated design, a lack of technical support, and unexpected costs.

The successful in-education integration of computers might necessitate devising plans for all learners, with emphasis placed on students' needs, as well as whether or not there is scope for computer use in the form of a learning instrument-a compensatory measure (ATD) or a substitute for learning so as to ensure the inclusion of learners in education whilst also ensuring students' scope of digital skills is utilised (Lidstrom, Granlund \& Hemmingsson, 2012). A case study work carried out in the USA by Gillette (2006) highlights the necessity to devise an Individual Educational Plan (IEP) for SEN students' utilisation of ICT in the school setting. The scholar further provides an overview of students with SEN in the seventh grade, as well as the team work recognised between the home, school and student, which ultimately facilitates the creation of a plan pertaining to the student's reading and writing through assistive technology. In this regard, it may be identified what aspects assistive technology involves and the way in which it is applied; these need to undergo evaluation in line with the ability, requirements and requests of the learner, with this approach necessitating expertise in assistive technology. Amongst the school, parents and student, there needs to be team work; this is recognised as paramount due to its capacity to facilitate the garnering of advantages by students in the use of ICT. As touched upon earlier, IT abandonment could arise if parents are not aware of how such tools should be applied (Gillette, 2006).

\subsection{ICT Uses in School}

ICT use between learners with physical disabilities and those without was compared in the study by Lidstrom et al. (2012), which drew the conclusion that those learners with physical disabilities have limited involvement when contrasted with those learners from the population as a whole, specifically in regards computer-based activities. The research is one aspect of a more wide-ranging initiative, focused on examining ICT adoption alongside involvement in activities encompassing computer use - both within as well as outside the learning setting. There was the completion of a questionnaire, targeting learners of 10-18 years both with and without difficulties, with the questionnaire centred on computers as assistive technology devices.

Learners' utilisation of ICT was divided by Lidstrom et al. (2012) in terms of whether ICT was used as another instrument for learning. When using the computer to research information on the internet, carry out word processing and create presentations, the computer is recognised as being used as a learning instrument. In this way, the computer might, in addition, be utilised as a different learning instrument, such as through online software and resources that make use of specific skillsets, for example. ICT adoption as an educational tool is most wide-ranging amongst those learners without difficulties. For those with SEN, however, the computer can, in addition, be applied as a learning instrument, although ICT may further be applied as a compensatory instrument in an effort to assist learners in compensating for the abilities they might not have. Such alternative tools might help learners with SEN to take advantage of the opportunity to be independently involved in the same activities as their non-SEN peers, such as by balancing activity-based restrictions whilst encouraging ICT use as an alternative instrument or educational instrument centred on education.

\subsection{Teachers Understanding of ICT Use for Special Needs Learners}

There is a pressing need for teachers to be familiar with the adoption of ICT for learners with SEN, in line with the American literature review centred on technical support in the learning setting for learners seen to have minor learning difficulties (Anderson, Anderson \& Cherup, 2009). Researches considered throughout the course of the review emphasise technology geared towards special education across various domains, including writing and 
reading, namely through the use of word prediction, word processors, spelling and grammar checks and text-to-speak, and their effects on the inclusive setting. Learners with minor disabilities might be seen in all classroom settings, meaning all teachers need to ensure awareness of the fact that technology integration can, for such students, facilitate learning.

\subsection{Summary of Previous Studies}

For those learners with SEN, ICT can be advantages, particularly amongst those with issues in writing and reading (Maor et al., 2011). Research supports the view ICT as being valuable in assisting with the writing of learners (Peterson-Karlan, 2011); however, it remains that there is a wealth of other advantages to be garnered by those with behavioural and/or emotional problems (Williams et al., 2006), in addition to those with problems of a physical nature (Lidstrom et al., 2012). In this context, ICT can be seen to facilitate educational access, as noted by Williams et al. (2006), as well as literacy in the literacy domain (Starcic, 2010). With this in mind, it is essential to consider adapting ICT in line with the individual requirements of students in order to ensure efficiency (Gillette, 2006). In this regard, all teachers need to ensure they are familiar with the use of ICT amongst learners with SEN as such students - all of whom can benefit from ICT - can be identified in all educational settings (Starcic, 2010). ICT possibilities are not widely utilised in teaching environments, with much recognition concerning both social and technical care in the ICT field in an effort to fill the void in inclusion for those with special needs (Brodin, 2010). Adopting ICT throughout the course of day-to-day education is problematic, as highlighted by Brodin (2010), with a further need for teaching staff, including SEN faculty, so as to ensure they are knowledgeable in ICT (Brodin \& Lindstrand, 2003). It is fundamental that teachers adapt ICT for students with SEN in the educational environment; however, realistically, very few modifications are adopted (Kargin, Basoglu \& Daim, 2009). Although ICT has the capacity to contribute to inclusion, a number of students have been physically excluded from the classroom environment in order to receive special education (Giota \& Emanuelsson, 2011). Such one-on-one teaching is seen to be more prevalent across the globe, with the aim of delivering access to technology for all learners (Penuel, 2006).

\section{Research Objectives}

This research's aim is centred on explaining and examining the viewpoints and experiences of teachers in how ICT can be used for learners with SEN in consideration to inclusion, and drawing a contrast of teachers across different grades. The study questions to be answered are as follows:

1. What are the viewpoints held by teachers in regard to ICT adoption for learners with SEN?

2. What are the viewpoints held by teachers in regard to the link between the inclusion of learners with SEN and ICT?

3. What approaches and conditions can be established in an effort to make ICT adoption more inclusive for students with SEN?

\section{Methodology}

Owing to the fact that the research seeks to establish the viewpoints of teachers pertaining to a particular phenomenon, phenomenography provides the rationale for the analyses of the interviews. Importantly, phenomenography may be defined as a research of an empirical nature, notably adopting different methods, in which the world's elements are encountered, which further encompasses the relationships between individuals and various elements of their world being mapped. One overall objective in phenomenography concerns providing explanations and examinations, as well as gaining insight into knowledge and experience created through descriptions of the conceptions around us (Marton, 1981). Through this model, emphasis is placed on the apprehended, conceptualised and the experienced. The goal is concerned with identifying and systemising different forms of thought.

Phenomenography may be described as an approach to qualitative analysis, pertaining to how individuals view a particular situation, with the perceived content pivotal (Punch \& Oancea, 2014). Phenomenographic studies are fundamentally concerned with the link between individuals and elements of the world; through this research, emphasis being placed on the relationship between faculty and the adoption of ICT surrounding the inclusion of learners with SEN. Within this domain, focus is placed on the very prevalence of the perspective, with the suggestion made by Marton (1981) the researcher should pose questions concerning the various conceptions people hold and the frequency of these, describing conceptions and categories. Importantly, conceptions are not recognised as individual qualities, but are recognised as different groupings of description warranting application in order to develop 
understanding into solid cases of human operations. Owing to the fact that the same description groups are recognised in various circumstances, the different groups are therefore considered generalisable and stable between settings, including when people change categories (Marton, 1981).

\subsection{Research Approach}

This study's objective was to describe the viewpoints of teachers in regard to ICT for those learners with SEN, and the link between ICT application and inclusion. Through the course of this study, interviews have been carried out in an effort to garner more in-depth insight into the viewpoints of twenty teachers concerning inclusion and teaching those students with SEN.

\subsection{Qualitative Interviews}

An interview may be explained as a qualitative approach, and is characterised by a lesser degree of formalisation than that identified in a questionnaire. The key aim of an interview is to gain understanding, with qualitative interviews providing a wealth of information on attitudes, approaches, experiences and views. Interviews, in this regard, are characterised by seeking to gain knowledge of the world in which the interviewee lives, as well as how they view themselves and their link to their surroundings (Neuman, 2014).

Interviews are applied in an effort to garner deeper information on the attitudes, actions and thoughts of people, such as when seeking to develop understanding of the reality of subjects as they see it. It is centred on everyday experiences, the interpretation of such, and understanding of the surrounding environment (Stukat, 2005). As has been highlighted by Patel \& Davidson (2011), interviews are an appropriate method when the objective of a research is to establish the actions, attitudes and experiences of a population. Owing to the fact that this study's aim is to describe, explain and examine the viewpoints of teachers, a qualitative interview is considered suitable.

The interview guide questions for this study were devised alongside the guidelines provided by Kvale \& Brinkmann (2009), with consideration to the study questions devised for the present research. Prior studies and theories have helped to devise the interview questions. The interview's aim was to establish more in-depth insight into the views of teachers in regard to the various inclusion-related elements in regards special needs learners and the use of ICT.

\subsection{Procedure}

Primarily, pilot interviews were carried out with SEN teachers. Subsequently, amendments were made to the interview guide. The respondents then were contacted on their phone numbers. Interviewees were required to talk freely and with confidence (Kvale \& Brinkmann, 2009); thus, there was the completion of interviews with different subject schools to facilitate this. The duration of the interviews was 35-55 minutes in duration, with all of them recorded, as suggested in the work of Berg \& Lune (2017). A key element inherent in phenomenographic interviews centres on ensuring empathy in an effort to ensure more wide-ranging involvement with the actual reality of people (Weinberg, 2002). Accordingly, in combination with emphatic answers and summaries, open questions were posed, which was recognised as helping interviewees to give the greatest possible wealth of data. As highlighted in the study of Kvale \& Brinkmann (2009), posing follow-up, detailed and probing questions, as well as silence, was carried out in mind of gaining insight into the perspectives of subjects, as well as identifying the meaning of their experiences.

There is a close link between conceptions and the actual experiences of people, and the identification and categorisation of ideas and thoughts, which ultimately may be considered an interview's objective (Berg \& Lune, 2017). Throughout the course of the interviews, the subjects were asked to consider and outline various elements of the questions so as to determine their own principal ideas.

Table 1 shows the demographic information of the participants:

Table 1. Demographic Information of Teachers $(\mathrm{N}=20)$.

\begin{tabular}{ccc}
\hline & Variable & Frequency \\
\hline \multirow{2}{*}{ Gender } & Male & 12 \\
& Female & 8 \\
\multirow{3}{*}{ Teaching Experience } & $(0-10)$ & 13 \\
& $(11-20)$ & 5 \\
\multirow{2}{*}{ Education } & $(21-30)$ & 2 \\
& Bachelor & 18 \\
& Master & 2 \\
\hline
\end{tabular}




\subsection{Interview Analyses}

Following the completion of the interviews, there was the transcription and subsequent categorisation, following the different conceptions of the interviewees. The overall and primary criteria for categorisation, in line with phenomenography, are the conceptions. In an effort to identify conceptions and accordingly categorise the findings, re-reading the interviews was carried out at various points, as suggested in the work of Weinberg (2002). The various explanations in this regard will be created through absolute consideration to the text that has been transcribed, with the scholar afforded the capacity to complete the interpretation, identification and labelling of the categories' names. Following categorisation, meaning condensation was applied in an effort to abbreviate the meanings described by the interviewees, making use of shorter statements, as noted in the work of Kvale \& Brinkmann (2009).

Upon the completion of the presentation of the results, the aim is centred on achieving balance in regards commenting text and quotations, as highlighted by Hennink, Hutter \& Bailey (2015). With this noted, the results undergo analysis through the theoretical framework relating to inclusion.

\subsection{Research Ethics}

Research ethics' rules, as detailed in the work of Mertens \& Ginsberg (2009), encompasses four different aspects, aimed at delivering principles concerning the link amongst subjects alongside the researcher, centred on encouraging a sound balance between study requirements and the protection of the individual's integrity. Studies should be carried out so that the study object's integrity is ensured, with ethical considerations, including confidentiality, informed consent and interviewee consequences, taken into account when carrying out a qualitative interview (Kvale \& Brinkmann, 2009). Study subjects needs to be informed in regard to the investigation purpose and the key aspects of the study design.

Noted by Mertens \& Ginsberg (2009), the first principle is concerned with informing the research subjects, with participation voluntarily. Throughout the course of this research, this principle has been fulfilled by the sending of a letter detailing the study aim, further detailing the fact that participation is voluntary, with the statement made that, at any time, participants can end their involvement in the study.

The second principle refers to consent, where the research subjects have the option of establishing whether or not they would like to be involved (Mertens \& Ginsberg, 2009). Throughout the course of the interviews, the subjects were again informed regarding the research aim and their option to end involvement at any stage.

The study subjects need to be assured of confidentiality as the third principle (Ana. 2008). Subjects should not be identified by anyone else besides the researcher. In the research carried out, no personal data were gathered. Throughout the interview transcripts, no personal names were used, but rather Interviewee 1, Interviewee 2, etc. were used. In an effort to ensure the subjects' identities are protected, very little data concerning their backgrounds was gathered. The respondents' names were not used, but rather aliases were used.

Principle 4 is concerned with how the research findings will be used. In this way, the data gathered is to be used only for the objective states, and not for any other purpose (Mertens \& Ginsberg, 2009). The interview results will not be used for any other research purpose.

\subsection{Reliability and Validity}

Reliability is centred on whether the situation is universal for all subjects, as well as whether questions may be considered universally by all involved. In this way, high reliability would mean another research would provide the same results (Weinberg, 2002). If questions are perceived differently by the subjects, one benefit could be the potential to directly ask questions in an effort to highlight the different viewpoints of the subjects.

The consideration of reliability is commonly referred to in regard to the question of whether or not the same results can be recreated at different points by other researchers (Kvale \& Brinkmann, 2009). In this research, professional and/or personal relationships are seen to be present between the respondents and the researcher, which could impact the interview results. Having a relationship with respondents could mean some of the results might not be considered, whereas others might be emphasised. Importantly, this could have a negative impact on impartiality (Kvale \& Brinkmann, 2009). Throughout the interviews, professionalism was ensured by keeping attention on the study area. When completing the interview transcriptions, reliability could have been greater had another individual completed the transcription process; interpretation might differ from one person to the next. However, the transcription was completed with attention to every word, with subsequent repeated listening so as to ensure the omission of errors.

Validity is centred on measuring that which requires measurement, as highlighted by Kvale \& Brinkmann (2009). In the work of Neuman (2014), the suggestion is made that question validation, in regard to the study aim, is achieved 
by completing a pilot study. In mind of ensuring the prevention of misunderstandings and errors, pilot works were completed prior to the final conduction of the interviews.

In the view of Kvale \& Brinkmann (2009), validity needs to be checked on an on-going basis throughout the entire interview approach. Notably, the findings need to undergo control and questioning, with the researcher completing a theoretical interpretation. Importantly, the consideration of validity not only centres on the ultimate outcome; rather, preparing, interviewing, transcribing, analysing and describing are critical. In the present research, there has been the control of the interview guide questions through the completion of a pilot study. Moreover, interviewees were questioned in such a way so as to ensure the information can be clarified, controlled and validates. During the transcription process, efforts have been made to ensure the language style was maintained. The results' analysis was carried out in order to ensure the subjects' actual perceptions were accurately portrayed.

\section{Results}

\subsection{ICT Use}

The viewpoints of teachers in regards prevalence of learners with SEN utilising ICT within the learning setting emphasise that most of them consider in-school use of ICT amongst learners with SEN to be fairly common. Notably, however, six of the teachers stated that they had never taught students with SEN who used ICT in the school environment, stating, 'In my teaching experience, those students with special needs have never been taught using ICT' (Interviewee 7). A number of the subjects, notably totalling 12, were found to have no understanding or knowledge of the various activities able to be facilitated through ICT use.

When considering the various areas of ICT use, participants stated that ICT can be used for:

- Searching out information (17)

- Communication (18)

- Writing and/or reading (16)

- $\quad$ Spell checkers (8)

- Photographs, music and sound, and video (19)

The perceptions of the teacher interviewees, when questioned on the use of ICT amongst students with SEN, have been broken down into two groups: the first centres on computer use as part of everyday education; the second concerns computers being used for particular reasons, such as writing and researching on the internet, for example. A number of teachers stated ICT use as a part of everyday education. their view of ICT is that it is a significant part of life and plays a valuable role for all students.

The perceptions of the other teachers in regards ICT show that computer use is predominantly for the purpose of writing, but also to some degree when researching on the internet and watching Photographs, music and sound, and video. Importantly, computers are recognised as used when, in the main, students are writing or looking for information or watching Photographs, music and sound, and video.

\subsection{ICT and Inclusion}

When questioned on whether or not teaching may undergo modification for learners with SEN adopting ICT within the classroom, there was the identification of three different categories, where teachers consider teaching to be adapted, adapted to some degree, or not adapted. Importantly, it was found that six teachers consider it to be adapted, whilst eight of them view it as adapted to some degree, whereas six teachers stated it is not adapted to any degree.

One of the teachers (Interviewee 6) emphasise the issues in planning lessons considering the adoption of ICT when learners are not afforded access to computer systems. One of the other respondents (Interviewee 17) emphasised his own displeasure on the fact that teachers are unsuitably prepared for providing students with appropriate materials for their ATDs, and another teacher (Interviewee 12) further noted that improvements in technological equipment are fundamental.

In regards the classroom setting for students with SEN who make use of ICT, the teachers were questioned on whether or not ATDs were used within and outside of the classroom. In relation to use within the classroom, a total of twelve teachers state that ATDs are often used by the teachers. Furthermore, a total of ten teachers stated that students are believed to use their ATDs outside of the classroom regularly.

One of the teachers (Interviewee 20) communicated that "students with access to computers in the school 
environment should be given both support and supervision, either on an individual basis or otherwise in groups, on the way in which devices should be and could be used".

The teachers were also questioned on whether they consider ATDs as having an effect in terms of social inclusion in the classroom. three categories were established: those recognising ICT as having an effect on students' social inclusion(13 teachers), those who did not feel there was an effect (5 teachers), and those who were uncertain(2 teachers).

When considering the perceptions of the teachers in regards whether or not ICT may contribute to inclusion, teachers believed that ICT is Valuable in regards Inclusion "For those learners with difficulties in writing and/or reading" (Interviewee 1), "In the case of those learners experiencing physical problems" (Interviewee 13), "It can encourage student independence" (Interviewee 4), "It permits individual, one-to-one instruction" (Interviewee 20), "technology can be very useful in overcoming impairments" (Interviewee 7), "would be useful in improving students' confidence and self-esteem" (Interviewee 9), "e-learning environments able to benefit students in terms of their ability to organise and plan their work in line with teachers' requests" (Interviewee 15).

\section{Discussion}

There was much diversity between the answers of the teachers interviewed, with no teacher seen to have the same view as another. The interviews can therefore be described as providing a number of different insights into this subject, which has provided valuable information and ultimately enriched the study.

\subsection{ICT Use}

Without question, the computer is the most widely used common assistive technology device adopted by students with SEN, as stated by teachers involved in the current study. Computers are commonly utilised for a variety of activities; however, the current study's results, as well as those garnered in other works, highlight the effectiveness of ICT adoption for those with writing and reading problems. Studies also note learners as needing to be providing with their own plans, encompassing the adaptation of ATDs in line with the individual requirements of students (Maor et al., 2011).

It is necessary for teachers to ensure adequate knowledge of ICT for students with SEN (Anderson et al., 2009); however, in line with the results of the interviews, it is recognised that a number of the teachers involved in the study lacked in knowledge in regard to many of the different activities offered by ICT. One potential factor could be different grades and years utilising ICT when completing various tasks, with older children's teachers potentially lacking awareness of the various activities that can be carried out by younger children. Second potential factor could be lack of the training received by teachers of students with SEN. This also could prove some insight into the possibility that teachers are lacking knowledge in various areas of ICT adoption.

When considering ICT application, it is recognised that ICT can be used both as an educational tool and also as a learning aid (Lidstrom et al., 2012). Importantly, studies carried out in the past, as well as the current work's findings, emphasise that ATDs may be able to give learners with SEN the chance to facilitate independent participation through completing the same tasks as non-SEN learners through balancing out task-related limitations. Nonetheless, there is the view that teaching staff may not necessarily be well informed as to how students can be helped with their ATDs, which results in the view that learners need to be left to work without assistance, without the provision of support or useful aids.

\subsection{ICT and Inclusion}

In order to best exploit and utilise ICT for SEN, a number of researches have emphasised the value of both ICT knowledge, and the adaptation and integration of teaching with assistive technology used, to be ensured by teachers (Anderson et al., 2009). Findings from the present work suggest that there is a lack of knowledge pertaining to ICT for students with SEN amongst teachers. Teachers are recognised as lacking in knowledge regarding all possibilities of ICT, with potential explanations including a lack of interest, a shortage of time and poor access to technology. Moreover, ICT for students with SEN might be recognised by teachers as special education teachers' role. Some teachers might think that working more with ICT would be preferable, but a lack of e-learning sources could be apparent. There has also been the expression for more help and supervision.

In the research, it is recognised that teachers perceive adaptations are needed in line with students' special educational needs, when such students utilise ICT in school. However, in the view of Kargin, Basoglu \& Daim (2008), adapting teaching is recognised as fundamental but, in the majority of cases, it is unclear the degree to which 
this is necessary, and whether such changes would be enough for students. As has been discussed by Kargin et al. (2008), various changes could be made easily, but may still be lacking for students. In line with the study's findings, the assumption could be made that students would be sitting in the classroom with their ATDs but without the presence of adapted teaching in line with their requirements.

There is a need for focus to be directed towards the role adopted by the special education teacher as a consultant for teachers or as a supervisor when considering modifying education for learners with SEN. Not all teaches are positioned to stay abreast with technological updates and how to work with ATDs; this sometimes warrants professionals. The SEN teacher is, in this regard, considered an expert in the domain of students with SEN and ICT use, with this perspective resulting in the exclusion of students in need of assistance. In contrast, viewing the SEN teacher as a teacher supervisor enables learners to remain in the classroom setting so as to ensure they are not neglected in terms of involvement in physical and social activities, rather than being made to use another classroom away from non-SEN learners so as to strive towards better understanding. In this vein, SEN teachers could be valuable in adapting materials and teaching rather than partaking in individual teaching with learners. The value of this for teachers is also recognised, with faculty then able to expand on their own teaching skills whilst being positioned to address SEN teachers' task of overcoming difficulties and obstacles in various teaching environments (Margalit, 2011). The findings garnered through this study in the support of Brodin \& Lindstrand (2003) suggest that it is not common for all SEN teachers to feel at ease with adopting the role of an ICT expert, with such special needs teachers requiring training in ICT. In this regard, the work of Penuel (2006) further recognised the value of other teachers in assisting teachers in utilising ICT within the teaching environment, meaning a number of advantages could also be achieved should opportunities and time be afforded to facilitate learning from each other in regards to ICT for special needs students.

Unquestionably, in considering the domain of inclusion, ICT is recognised as a positive and pivotal factor in relation to the involvement of consistent social inclusion and teaching in line with the present work's findings. ICT is positioned to enable learning access; this can prove valuable in enhancing levels of motivation and accordingly enhance confidence and self-esteem, in the view of Williams et al. (2006); which were confirmed in the finding of the current study. The results garnered in this work do suggest that ICT is well positioned to add value in terms of learners' inclusion when they are faced with problems in writing and/or reading, as well as those learners experiencing more physical problems. This provides validation of those studies carried out in the past (Peterson-Karlan, 2011). Moreover, ICT could facilitate student independence, enabling e-learning environments and individualised instruction to be used, which could be beneficial to the inclusion of students in line with the current study.

In the present study, the teachers recognise a number of elements that could position ICT use for students with SEN as valuable, and thus proving useful for more inclusive education. Primarily, knowledge relating to technology, the needs of students and how students can be helped is communicated. The results garnered are supported by other studies that emphasise the value of knowledge as held by teachers (Anderson et al., 2009). It appears that teachers direct their efforts towards adapting teaching and accordingly including students with SEN through the use of ICT, although their levels of knowledge in this arena are usually lacking.

\section{Implications}

The study's findings have a number of implications in regard to the endeavours of mainstream and special needs teachers within the teaching setting. Classroom teaching should undergo adaptation in line with the needs of students so as to facilitate didactic inclusion. One issue concerning SEN teachers being viewed as experts on the use of assistive technology, which results in students being removed from regular classes. In contrast, SEN teachers should direct their efforts towards examining the individual needs of the students and teaching how adaptations can be implemented so as to allow the student to learn in the classroom. Teachers should be assisted with how teaching can be adapted for special needs learners adopting in-class ICT in an effort to garner all ICT-related advantages, meaning ICT may be able to act as a way of facilitating inclusion for all students (Brodin, 2010).

Importantly, SEN teachers being given training in ICT is not adequate, but rather will emphasise the role of the SEN teacher as affording special support. Rather, there is a need for all teaching staff to place emphasis on ICT when teaching, whilst the role of the SEN teacher is centred on establishing students' requirements and accordingly to help teachers to adapt their practices in line with the individual needs of the student. Teachers need to be educated on the use of ICT for all students as well as for students with SEN. 


\section{Further Research}

Additional work is recognised as necessary in regards ICT for special needs learners. Subsequent works might direct attention to the views of students pertaining to ICT in facilitating inclusion. Such efforts could provide contributions in terms of developing insight into how teachers execute lessons for those with special need through the use of ICT in the school setting. One further suggestion could be to complete a comparable work in a setting where learners are provided with computer systems in an effort to establish whether or not individual teacher-to-student learning might be able to encourage and facilitate inclusion of learners with SEN.

\section{Conclusions}

There are varying viewpoints concerning what inclusion encompasses, with inclusion considered to be didactic, which can result in both physical and social exclusion. In the mainstream school environment, teaching has not always been modified in line with the needs of students, with assistive technology commonly implemented by learners in private environments. So as to ensure the use of ICT is more wide-ranging, there is the need to ensure the equipment, knowledge and time available to teaching staff are fulfilled, with teachers' and teacher educators' implications including that teachers need to be better educated in regard to ICT for SEN, with special education teachers needing to be viewed as teachers' supervisors.

\section{Acknowledgements}

This project was funded by the Deanship of Scientific Research (DSR) at King Abdualziz University, Jeddah, under grant no. G-580-324-38. The author, therefore, acknowledge with thanks DSR for technical and financial support.

\section{References}

Ana, S. (2008). Research Ethics. London: Routledge.

Anderson, C. L., Anderson, K. M., \& Cherup, S. (2009). Investment vs. Return: Outcomes of Special Education Technology Research in Literacy for Students with Mild Disabilities. Contemporary Issues in Technology and Teacher Education (cite Journal), 9(3), 337-355.

Berg, B. L., \& Lune, H. (2017). Qualitative research methods for the social sciences. Boston: Pearson.

Brodin, J. (2010). Can ICT give children with disabilities equal opportunities in school?. Improving Schools, 13(1), 99-112. https://doi.org/10.1177/1365480209353483

Brodin, J., \& Lindstrand, P. (2003). What about ICT in special education? Special educators evaluate information and communication technology as a learning tool. European Journal of Special Needs Education, 18(1), 71-87. https://doi.org/10.1080/0885625032000042320

Dyal, A., Carpenter, L. B., \& Wright, J. V. (2009). Assistive Technology: What Every School Leader Should Know. Education, 129(3), 556-560.

Gillette, Y. (2006). Assistive Technology and Literacy Partnerships. Topics in Language Disorders, 26(1), 70-84. https://doi.org/10.1097/00011363-200601000-00007

Giota, J., \& Emanuelsson, I. (2011). Policies in Special Education Support Issues in Swedish Compulsory School: A Nationally Representative Study of Head Teachers' Judgements. London Review of Education, 9(1), 95-108. https://doi.org/10.1080/14748460.2011.550439

Hennink, M., Hutter, I., \& Bailey, A. (2015). Qualitative research methods. London: SAGE Publications Ltd.

Istenič, S. A. (2010). Educational technology for the inclusive classroom. The Turkish Online Journal of Educational Technology, 9, 26-37.

Jane, B. (2010). Can ICT give children with disabilities equal opportunities in school?. Improving Schools, 13(1), 99-112. https://doi.org/10.1177/1365480209353483

Kargin, B., Basoglu, N., \& Daim, T. (2008). Exploring mobile service adoption: A conjoint model. Proceedings of Portland International Center for Management of Engineering and Technology, 27(31), 2623-2633. https://doi.org/10.1109/PICMET.2008.4599891

Kargin, B., Basoglu, N., \& Daim, T. (2009). Factors affecting the adoption of mobile services. International Journal of Services Sciences, 2(1), 29-52. https://doi.org/10.1504/IJSSCI.2009.021960 
Kvale, S. \& Brinkmann, S. (2009). Interviews: learning the craft of qualitative research interviewing. Thousand Oaks, CA: Sage.

Lidstrom, H., Granlund, M., \& Hemmingsson, H. (2012). Use of ICT in School: A Comparison between Students with and without Physical Disabilities.European Journal of Special Needs Education, 27(1), 21-34. https://doi.org/10.1080/08856257.2011.613601

Maor, D., Currie, J., \& Drewry, R. (2011). The effectiveness of assistive technologies for children with special needs: a review of research-based studies.European Journal of Special Needs Education, 26(3), 283-298. https://doi.org/10.1080/08856257.2011.593821

Margalit, M. (2011). Effective technology integration for disabled children: The family perspective. New York: Springer.

Marton, F. (1981). Phenomenography - describing conceptions of the world around us. Instructional Science, 10, 177-200. https://doi.org/10.1007/BF00132516

Mertens, D. M., \& Ginsberg, P. E. (2009). The handbook of social research ethics. Los Angeles: Sage Publications. https://doi.org/10.4135/9781483348971

Neuman, W. L. (2014). Social research methods: Qualitative and quantitative approaches. Harlow, Essex: Pearson.

Penuel, W.R. (2006). Implementation and effects of one-to-one computing initiatives: A research synthesis. Journal of research on technology in education, 38(3), 329-348. https://doi.org/10.1080/15391523.2006.10782463

Peter, W., Hamid, R. J., \& David, N. (2006). Using ICT with people with special education needs: what the literature tells us. Aslib Proceedings: New Information Perspectives, 58(4), 330-345. https://doi.org/10.1108/00012530610687704

Peterson-Karlan, G. R. (2011). Technology to Support Writing by Students with Learning and Academic Disabilities: Recent Research Trends and Findings. Assistive Technology Outcomes and Benefits, 7(1), 39-62.

Punch, K., \& Oancea, A. (2014). Introduction to research methods in education. London: Thousand Oaks, California: SAGE Publications Ltd.

Sik-Lányi, C., Hoogerwerf, E.-J., Miesenberger, K., \& Cudd, P. (2015). Assistive technology: Building bridges. Amsterdam: IOS Press.

Starcic, A. I. (2010). Educational Technology for the Inclusive Classroom. Turkish Online Journal of Educational Technology - Tojet, 9, 3, 26-37.

Stukat, S. (2005). To write essays in education. Lund: Studentlitteratur.

Sverige, \& Sverige. (2001). Curriculum for the non-compulsory school system: Lpf 94. Stockholm: Ministry of Education and Science in Sweden, Regeringskansliet.

Sverige. (2006). Curriculum for the compulsory school system, the pre-school class and the leisure-time centre Lpo 94. Stockholm: Swedish National Agency for Education (Skolverket.

Unesco. (1994). The Salamanca statement and framework for action on special needs education: World conference on special needs education : access and quality : Salamanca, Spain 7-10 June 1994. Paris: UNESCO.

Unesco. (2005). Guidelines for inclusion: Ensuring access to education for all. Paris: United Nations Educational, Scientific, and Cultural Organization.

Weinberg, D. (2002). Qualitative research methods. Malden, MA: Blackwell Publishers.

Williams, P., Jamali, H. R., \& Nicholas, D. (2006). Using ICT with people with special education needs: what the literature tells us. Aslib Proceedings, 58(4), 330-345. https://doi.org/10.1108/00012530610687704 